\title{
Peertechz
}

\section{Respiratory system}

pathologies in patients who

underwent total laryngectomy

\section{due to larynx cancer}

\section{Hakan Celikhisar*}

Chest Diseases Specialist, Izmir University of Economics, Vocational School of Health Science, Izmir, Turkey

\section{Abstract}

Aim: The aim of the present study was to examine the long-term respiratory system pathologies that may develop in larynx cancer patients who have undergone total laryngectomy operation.

Method: A total of 54 larynx cancer patients who have undergone total laryngectomy operation admitted to our clinic during July 2016 - November 2019 due to accompanying respiratory system pathology were retrospectively evaluated with regard to clinical radiologic and histopathologic findings. The findings were examined comparatively with relevant literature data.

Results: All cases were male with an age average of $65+8$ years. The cases had a smoking history of $62+42$ packs/year on average. All cases had been subject to total laryngectomy operation due to epidermoid type larynx carcinoma and they had tracheostomy. Non-small cell lung carcinoma was determined in 14 cases ( $26 \%$ ), chronic obstructive pulmonary disease (COPD) in 12 cases (22\%), pneumonia in 8 cases (15\%), inactive lung tuberculosis in 4 cases (7.5\%), malignant pleurisy in 2 cases ( 3.75 $\%)$ and metastatic lung cancer in 2 cases (3.75\%).

Conclusion: The pathologies observed in the cases were predominantly evaluated secondary to tracheostomy and epidemiologic factors such as smoking. It was concluded that operated larynx cancer cases should be followed up at frequent intervals with regard to other respiratory system pathologies that may develop.

\section{Introduction}

Laryngeal cancer continues to be the most widespread tumors of the head and neck regions [1,2]. Despite the significant advancements in the care of laryngeal cancer patients during the last several decades, therapeutic complications and the increased attention to quality of life have led to the need to carry out further studies on this population [3]. In addition to laryngeal malignity itself, factors related to acute and late or chronic treatment, secondary primary cancers, intercurrent disease and psychosocial factors are responsible from patient morbidity and mortality. Loss of the protective function of the nose and upper respiratory tracts resulting from the total laryngectomy operation due to larynx cancer make these cases more sensitive to lung infections in comparison with normal individuals [4]. Hence, all patients should be evaluated in a multidisciplinary environment and should have a detailed treatment and rehabilitation plan based on the results of this evaluation. Moreover, the fact that smoking as the primary factor in larynx cancer etiology is also the primary factor for COPD and lung cancer etiology and the fact that about $25 \%$ of the head-neck region cancers metastasize in the lungs result in frequent respiratory system pathologies in these cases $[5,6]$. The purpose of the present study was to examine the long term respiratory system pathologies that may develop in larynx cancer patients who have undergone total laryngectomy operation, determine the possible respiratory issues in laryngectomy patients before they develop and develop rehabilitation programs for those that are determined. 


\section{Materials and method}

A total of 54 larynx cancer patients who have undergone total laryngectomy operation admitted to our clinic during July 2016-November 2019 due to accompanying respiratory system pathology were retrospectively evaluated with regard to clinical radiologic and histopathologic findings. The median age of the patients was $65+8$ and all the cases were male. Histopathological diagnosis was made by biopsy in all cases. The youngest patient was 37 years old, and the oldest was 79 years old. Four $(7 \%)$ of the cases had chemotherapy and 36 $(33 \%)$ of them had simultaneous chemo-radiotherapy and all of them were regional hyperfractionated radiotherapy. The findings were examined comparatively with relevant literature data. The study was approved by the local ethics committee and informed consent was obtained from the study participants.

\section{Statistical analysis}

Statistical Package for the Social Sciences (SPSS, Inc. Chicago IL) version 22 was used for data analysis the results of which were presented as mean \pm standard deviation, number (n) and percentage (\%). $\mathrm{X}^{2}$ test was used for the comparison of categorical variables between groups, whereas Student $\mathrm{T}$ test was used for comparing continuous variables. P values of $<0,05$ were accepted as statistically significant.

\section{Results}

Fifty-four patients underwent the procedure and were followed up for at least 48 mounts or until death. Incidence of distant metastases was greatest between 1.5 and 4 years after initial treatment with a mean incidence being less than or equal to 3.2 years. Seventeen underwent the surgery for recurrence after failure of radiation therapy for cure. All cases were male. Age average was $65+8$ years. They had a smoking history of $62+42$ packs per year on average. All cases had undergone total laryngectomy operation due to epidermoid type larynx carcinoma and had tracheostomies. The respiratory system pathologies observed in the cases are summarized in Table 1.

Table 1: Respiratory system pathologies observed in laryngectomy patients.

\begin{tabular}{|c|c|c|}
\hline Respiratory system pathology & $\mathrm{n}$ & $\%$ \\
\hline Non-small cell lung carcinoma & 14 & 26 \\
\hline COPD & 12 & 22 \\
\hline Pneumonia & 8 & 15 \\
\hline Inactive lung tuberculosis & 4 & 7.5 \\
\hline Malignant pleurisy & 2 & 3.7 \\
\hline Metastatic lung cancer & 2 & 3.7 \\
\hline Esophagus carcinoma + esophagus-pleural fistula & 2 & 3.7 \\
\hline Hamartoma & 2 & 3.7 \\
\hline Lung abscess & 2 & 3.7 \\
\hline Costa osteomyelitis & 2 & 3.7 \\
\hline Solitary pulmonary nodule & 2 & 3.7 \\
\hline Mass lesion + pleural fluid & 2 & 3.7 \\
\hline
\end{tabular}

Of the cases with non-small lung carcinoma, 12 were squamous cell carcinoma and 2 were adenocarcinoma. Twelve of these cases were Stage 3B, whereas one was Stage $1 \mathrm{~A}$. The average duration until the lung carcinoma patients applied to our hospital following laryngectomy was $48+36$ months. Smoking histories were $70+41$ packs-year.

The case with malignant pleurisy applied to our hospital 84 months after laryngectomy. The patient was diagnosed with pleural function cytological examination. Cytological findings were in accordance with adenocarcinoma metastasis Primary focus was not observed in the patient examined via fiberoptic bronchoscopy, thorax and computerized abdominal tomography.

One case was hospitalized on the $12^{\text {th }}$ month after laryngectomy due to bilateral multiple metastatic nodules in the lung. No other primary focus was observed as a result of bronchoscopy and the examination of other systems. However, it was later found that the prostate cancer had lung metastasis.

Esophagus-pleural fistula was determined in a patient who had undergone laryngectomy at another center after which epidermoid type esophagus carcinoma was determined on the $46^{\text {th }}$ month who had been referred to our hospital due to pleural effusion in the left hemithorax following diagnosis. The esophagopleural fistula diagnosis was placed following the detection of food particles in the drainage fluid and via barium esophagus passage graphy in the patient subject to closed water-seal drainage due to the detection of empyema in pleural puncture.

Rigid bronchoscope was used for excision of the polypoid appearance mass detected at the $1 / 3$ distal end anterior localization in the trachea after which it was reported as hamartoma following the pathological examination.

Twelve of the patients (22\%) had previously diagnosed COPD disease. These cases were first hospitalized at our service due to acute flare up on average about $87+64$ months following laryngectomy. Their hospitalizations for the same reason were excluded from the present study. The smoking histories of these cases were $44+30$ packs per year on average.

Pneumonia was detected in 8 cases $(15 \%)$, whereas lung abscess was detected in 2 cases $(3.7 \%)$. Stafilococcus Aerius grew in the non-specific phlegm culture of one of the cases who applied with pneumonia clinic, whereas Acinetobacter grew in one of the cases with lung abscess both of which ended with exitus. The factor could not be isolated in the other 7 cases with pneumonia, however they benefited from the empirical antibiotherapy applied.

Chronic osteomyelitis was determined via partial rib resection in 1 patient who applied with swelling and pain in the right $5^{\text {th }}$ and $6^{\text {th }}$ costochondral junction.

Solitary pulmonary nodule was present in two out of 4 cases $(7.5 \%)$ who could be subject to radiological examination, bilateral multiple pulmonary nodules were present in one and mass lesion accompanying the pleural fluid in the right lung 
was present in the other. Further examinations could not be carried out on these cases since they did not accept diagnostic procedures.

\section{Discussion}

Lung is generally the first location of metastasis in headneck cancers. However, it is also accepted that separate from these primary head-neck cancers, lung cancers can develop at a high rate as a second primary cancer type with novo carcinogenesis $[7,8]$. Even though a pulmonary shadowing frequently points out a metastasis in patients who had malignant tumors previously, a secondary primary cancer is also not very rare. Tumors observed in the head-neck region such as squamous cell carcinoma are related with increased secondary primary cancer probability in the lungs $[9,10]$. It is indicated that a solitary mass in the lung of the patient aged above 35 with a history of squamous cell carcinoma in the head-neck region should generally be evaluated as a separate primary cancer type. However, while an extrapulmonary tumor is bone or soft tissue sarcoma or a malignant melanoma will indicate that the lung tumor can be a metastasis, the clinical and pathological findings in a patient with previous pulmonary nodule, extrapulmonary adenocancer story will not be reliable for separating a new primary from metastasis [11,12]. Only one case in our study was evaluated as larynx carcinoma related metastatic lung cancer due to the presence of multiple nodules and the fact that a primary focus could not be determined in other systems. Lepainteur et al. applied lung graphy and fiberoptic bronchoscopy on each case at intervals of 6 months in order to examine the lung cancer prevalence following laryngectomy due to larynx cancer in a 3 year period as a result of which lung cancer was reported in $36(12.5 \%)$ out of 286 cases. While there were no clinical findings or findings in the lung graphies of these 36 cases, the diagnosis was placed via systematic fiberoptic bronchoscopy and surgery was possible in only 7 cases [13]. Similarly, An et al. determined lung metastasis in 38 cases out of the 48 larynx cancer cases with distant metastasis (14). Respiratory system malignity was detected in $16(29.6 \%)$ out of 54 cases in our study subject to total laryngectomy due to larynx cancer. All cases with malignant lesions in their lungs had applied at the inoperable stage excluding one patient with Stage $1 \mathrm{~A}$ lung carcinoma who could not be operated due to low performance.

The loss of protective functions in the nose and upper respiratory tracts render tracheostomy patients more prone to severe lung infections. It was determined following the ultastructural examination of the respiratory mucosa of these types of cases that degeneration and cilia loss developed in cilia cells due to decrease in the number of goblet cells especially during the postoperative 6 month period $[15,16]$. Smoking related COPD is frequently observed in majority of these cases and the failure to effectively expectorate the respiratory tract secretions in COPD cases further increases the risks of infection [17]. Of the 54 cases in our study, $12(22 \%)$ applied with COPD acute flare up, $8(15 \%)$ with pneumonia and $2(3.7 \%)$ with lung abscess. Stafilococcus Aerius grew in the non-specific phlegm culture of one of the cases who applied with pneumonia clinic, whereas Acinetobacter grew in one of the cases with lung abscess both of which ended with exitus. It is also indicated in literature that the prevalence of enteric gram negative bacillus increases in the tracheobronchial tree in those with long term tracheostomy [18]. In addition, Li et al. reported that the presence of tracheostomy poses an independent risk factor for Acinetobacter development [19]. It is suggested that the patients are taken in bronchial hygiene training programs for protection against severe lung infections by way of repressing the mucus $[20,21]$. Repeating infections may lead to rare complications such as the costa osteomyelitis observed in one of our cases $[22,23]$.

This study has various limitations that should be indicated. The fact that all cases who took part in the study are male was the most important limiting factor. This restricts our ability to generalize the findings of the present study.

Majority of the cases with tracheostomy who have been operated due to larynx cancer are generally followed up by ear nose throat clinics. Moreover, lung problems of these type of cases which do not require hospitalization are most probably treated at $1^{\text {st }}$ Level health institutions. These two factors are considered as the reason why majority of the cases with lung cancer are determined at advanced stages as well as the low number of cases in our study. Since larynx cancer is a headneck tumor with the highest prevalence, its treatment and prognosis are very important. Yllmaz; et al. reported the causes of death in larynx cancer cases as tumor with a ratio of $52 \%$, tumor related distant metastasis and secondary primary tumor intervention $[24,25]$. In our study incidence of distant metastases was greatest between 1.5 and 4 years after initial treatment with a mean incidence being less than or equal to 3.2 years. To obtain higher cure rates, it will be important to diagnose distant and delayed regional metastasis and second primary tumors at an earlier stage. Routine clinical evaluations and radiological examinations (computed tomography, magnetic resonance imaging, positron emission tomography scan, etc.) can result in significant salvage of delayed regional tumor metastases. Therefore, diagnosis on a molecular level using the polymerase chain reaction would facilitate early tumor detection and possibly increase cure rate and survival. Early detection and treatment of local recurrence, management of functional deficiencies due to treatment, and early detection of secondary primary carcinomas should be essential for the follow-up of patients with laryngeal cancer. Early detection and treatment of local recurrence, management of functional deficiencies due to treatment, and early detection of secondary primary carcinomas should be essential for the follow-up of patients with laryngeal cancer. Thus, cases who have undergone total laryngectomy due to larynx cancer should be closely followed up at frequent intervals with regard to common epidemiological factors such as smoking and secondary lung pathologies as well as the metastases of the first primary disease. We hope that the detection of the respiratory pathologies examined in larynx cancer patients will act as a guide for future interventions for improving the quality of life of these individuals. 


\section{References}

1. Gupta B, Johnson NW, Kumar N (2016) Global Epidemiology of Head and Neck Cancers: A Continuing Challenge. Oncology 91: 13-23. Link: https://bit.ly/2zReWMz

2. Chen L, Zhang M, Li C, Tao L, Wang SY, et al. (2017) Clinical analysis of neuroenddocrine carcinoma of the larynx. Lin Chung Er Bi Yan Hou Tou Jing Wai Ke Za Zhi 31: 1797-1799. Link: https://bit.ly/2WhiQGa

3. Jumaily M, Faraji F, Zhang D, Walker RJ, Ward GM (2019) Basaloid Squamous Cell Carcinoma of the Larynx: A National Cancer Database Analysis. Otolaryngol Head Neck Surg 160: 847-854. Link: https://bit.ly/2SrpCrk

4. Buiret G, Gautheron L, Labrosse-Canat H (2016) Tracheotomy/Tracheostomy Management at Home and in Care Centers. Arch Otolaryngol Rhinol 2: 061 069. Link: https://bit.ly/3fdri1R

5. Nemr K, Raquel ACS, Takeshita-Monaretti TK, Pires-Buzanelli E, SimõesZenari M, et al. (2015) Scientific Evidence Regarding the Quality of Life of Total Laryngectomees. Arch Otolaryngol Rhinol 1: 037-045. Link: https://bit.ly/2xwiHq0

6. Woodard TD, Oplatek A, Petruzzelli GJ (2007) Life After Total Laryngectomy: A Measure of Long-term Survival, Function, and Quality of Life. Arch Otolaryngol Head Neck Surg 133: 526-532. Link: https://bit.ly/35mPQRv

7. Sapkota A, Gajalakshmi V, Jetly DH, Roychowdhury S, Dikshit RP, et al. (2008) Indoor air pollution from solid fuels and risk of hypopharyngeal/laryngeal and lung cancers: a multicentric case-control study from India. Int J Epidemiol 37: 321-328. Link: https://bit.ly/2KUmdh0

8. Sabra MM, Sherman EJ, Tuttle RM (2017) Tumor volume doubling time of pulmonary metastases predicts overall survival and can guide the initiation of multikinase inhibitor therapy in patients with metastatic, follicular cell-derived thyroid carcinoma. Cancer 123: 2955-2964. Link: https://bit.ly/3fdEGCP

9. Swanton C, Govindan R (2016) Clinical implications of genomic discoveries in lung cancer. N Engl J Med 374: 1864-1873. Link: https://bit.ly/2SvPhQ6

10. McIntyre A, Ganti AKJJoso (2017) Lung cancer-a global perspective. J Surg Oncol 115: 550-554. Link: https://bit.ly/2VTZI7q

11. Schoenhals JE, Seyedin SN, Anderson C, Brooks ED, Li YR, et al. (2017) Uncovering the immune tumor microenvironment in non-small cell lung cancer to understand response rates to checkpoint blockade and radiation. Trans Lung Cancer Res 6: 148-158. Link: https://bit.ly/3bYmRFQ

12. Stevic R, Milenkovic B (2016) Tracheobronchial tumors. J Thorac Dis 8: 3401 3413. Link: https://bit.ly/2KUpY5P

13. Nunes Da Silva G, Miranda M, Rodrigues D, De Souza G, Ribeiro CJAOR (2019) Epidemiological factors in patients with larynx cancer treated by surgery, radiotherapy or therapeutic associations. Arch Otolaryngology 5: 043-049. Link: https://bit.ly/2z2aSJ3

14. Lepainteur M, Ogna A, Clair B, Dinh A, Tarragon C, et al. (2019) Risk factors for respiratory tract bacterial colonization in adults with neuromuscular or neurological disorders and chronic tracheostomy. Respir Med 152: 32-36. Link: https://bit.ly/2Ss3vRX

15. An JH, Kim YH, Moon JE, Jeong JH, Kim SH, et al. (2017) Active surveillance for carbapenem-resistant Acinetobacter baumannii in a medical intensive care unit: Can it predict and reduce subsequent infections and the use of colistin? Am J Infect Control 45: 667-672. Link: https://bit.ly/2Ss30w5

16. Tzelepis GE (2018) Chest Wall Diseases: Respiratory Pathophysiology. Clin Chest Med 39: 281-296. Link: https://bit.ly/3de8TQJ
17. Tiple C, Stamate MC, Ujvary LP, Chirilă M, Vesa ŞC, et al. (2019) Pulmonary rehabilitation in patients with total laryngectomy. Human and Veterinary Medicine 11: 122-125. Link: https://bit.ly/3bXkX8v

18. Pan Y, Hong Y, Liang Z, Zhuang W, et al. (2019) Survival analysis of distant metastasis of laryngeal carcinoma: analysis based on SEER database. Eur Arch Otorhinolaryngol 276: 193-201. Link: https://bit.ly/3feMqVd

19. Karaoglu D, Kocyigit M, Ortekin SG, Adali MK (2017) Late-term Effects of Surgery on Nasal Functions in Patients who Underwent Total Laryngectomy Surgery. Int Arch Otorhinolaryngol 21: 270-275. Link: https://bit.ly/2VWOhqj

20. Li FJ, Starrs L, Burgio G (2018) Tug of war between Acinetobacter baumannii and host immune responses. Pathog Dis 76: ftz004. Link: https://bit.ly/2Ssm7RX

21. Hsu CM, Ding MC (2018) Pulmonary Infection or Pneumonia in Patients Who Undergo Total Laryngectomy. International Journal of Head and Neck Science 2: 176-180. Link: https://bit.ly/2zL6NZT

22. Tsai CT, Ho MW, Lin D, Chen HJ, Muo CH, et al. (2016) Association of Head and Neck Cancers in Chronic Osteomyelitis: A National Retrospective Cohort Study. Medicine 95: e2407. Link: https://bit.ly/2Whtbln

23. Massa ST, Osazuwa-Peters N, Christopher KM, Arnold LD, Schootman M, et al (2017) Competing causes of death in the head and neck cancer population. Oral Oncol 65: 8-15. Link: https://bit.ly/2zRBkFF

24. Gross JS, Smith RJ (2016) Squamous Cell Carcinoma of the Larynx. Ultrasound Q 32: 307-309.

25. Nunes Da Silva GHB, Miranda MG, Rodrigues DS, De Souza GR, Ribeiro CV (2019) Epidemiological factors in patients with larynx cancer treated by surgery, radiotherapy or therapeutic associations. Arch Otolaryngol Rhinol 5 : 043-049. Link: https://bit.ly/3aWLkdw

\section{Discover a bigger Impact and Visibility of your article publication with}

\section{Peertechz Publications}

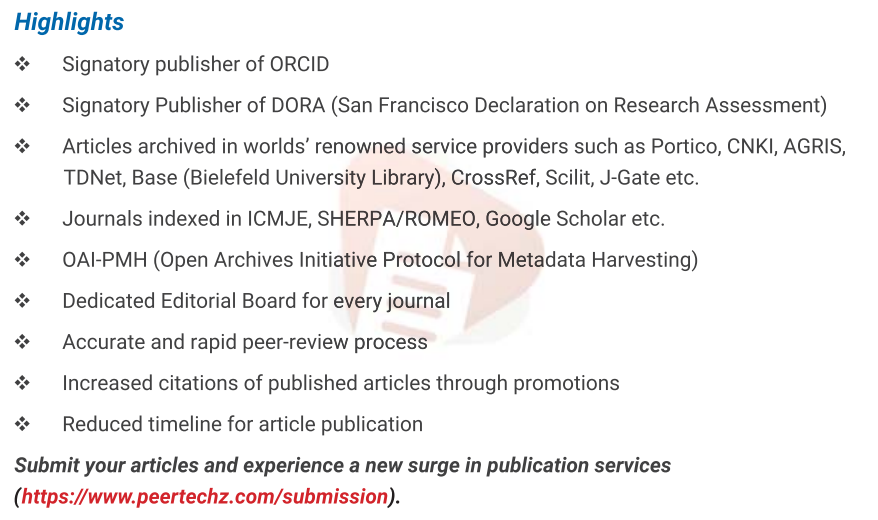

Peertechz journals wishes everlasting success in your every endeavours.

Copyright: @ 2020 Celikhisar H. This is an open-access article distributed under the terms of the Creative Commons Attribution License, which permits unrestricted use distribution, and reproduction in any medium, provided the original author and source are credited. 